\title{
Total Dose and Bias Temperature Stress Effects for HfSiON on Si MOS Capacitors
}

\author{
D. K. Chen, F. E. Mamouni, X. J. Zhou, R. D. Schrimpf, D. M. Fleetwood, K. F. Galloway, S. Lee, H. Seo,
}

G. Lucovsky, B. Jun, and J. D. Cressler

\begin{abstract}
We have performed an experimental study of the effects of ionizing radiation and bias-temperature stress on Si MOS devices with $\mathrm{HfSiON}$ gate dielectrics. We compare the responses of homogeneous high-Si $\mathrm{N}_{3} \mathrm{~N}_{4}$ films and low- $\mathrm{Si}_{3} \mathrm{~N}_{4}$ films that contain crystalline $\mathrm{HfO}_{2}$. We observe that the low- $\mathrm{Si}_{3} \mathrm{~N}_{4}$ films are more sensitive to ionizing radiation than the high-Si ${ }_{3} \mathrm{~N}_{4}$ films. In particular, the low- $\mathrm{Si}_{3} \mathrm{~N}_{4}$ film that includes crystalline $\mathrm{HfO}_{2}$ is especially vulnerable to electron trapping due to substrate injection under positive irradiation bias. Both film types exhibit reduced radiation-induced charge trapping relative to previous Hf silicates. The high-Si ${ }_{3} \mathrm{~N}_{4}$ film exhibits $16 \times$ less radiation-induced net oxide-trap charge density than earlier $\mathrm{Hf}$ silicate films processed without nitride. We also find that these devices are relatively robust against bias-temperature stress instabilities. Consistent with the radiation response, the low-Si ${ }_{3} \mathrm{~N}_{4}$ devices also display elevated levels of charge trapping relative to the high-Si ${ }_{3} \mathrm{~N}_{4}$ devices during bias-temperature stress.
\end{abstract}

Index Terms-Alternative dielectrics, bias-temperature instability, HfSiON, nitridation, total-dose irradiation.

\section{INTRODUCTION}

A LTERNATIVE gate dielectrics are rapidly becoming necessary to the future of advanced semiconductor technology as the $\mathrm{SiO}_{2}$ MOSFET reaches scaling limits. Gate leakage current becomes unmanageable as the gate oxide shrinks to the $10-\AA$ regime. High-k dielectrics permit a physically thicker gate insulator, thereby reducing the gate leakage [1]. Hafnium oxide has emerged as a strong candidate due to its thermal stability and higher dielectric constant relative to other high-k transition metal atom dielectrics. On the other hand, other $\mathrm{Hf}$ alloys with lower dielectric constants, e.g., Hf silicates and $\mathrm{Hf} \mathrm{Si} \mathrm{oxyni-}$ trides, offer improved interface qualities, but in the case of the silicates display a chemical phase separation that limits processing temperatures. The incorporation of nitrogen in Hf silicate films improves thermal stability and blocks dopant diffusion [2], [3]. However, metallic Hf-N bonding can decrease the band gap and reduce band offsets, thereby increasing gate

Manuscript received July 20, 2007; revised September 19, 2007. This work was supported in part by the Air Force Office of Scientific Research through the AFOSR MURI program.

D. K. Chen, F. E. Mamouni, X. J. Zhou, R. D. Schrimpf, D. M. Fleetwood, and K. F. Galloway are with the Department of Electrical Engineering and Computer Science, Vanderbilt University, Nashville, TN 37235 USA (e-mail: dakai.chen@vanderbilt.edu).

S. Lee, H. Seo, and G. Lucovsky are with the Department of Physics, North Carolina State University, Raleigh, NC 27695 USA.

B. Jun and J. D. Cressler are with the Department of Electrical Engineering and Computer Science, Georgia Institute of Technology, Atlanta, GA 30332 USA.

Digital Object Identifier 10.1109/TNS.2007.910862 leakage current [3], [4]. Various studies on HfSiON films conclude that these devices are suitable for low power applications [5]-[7].

Total-dose irradiation data on $\mathrm{HfSiON}$ films are at present very limited. For example, previous work by Felix et al. . [6], [8] focused on Hf silicates with no nitride processing, and Felix et al.. [9] and Zhou et al.. [10]-[12] reported on $\mathrm{HfO}_{2}$ based devices where nitride processing was confined to a thin silicon oxynitride surface layer. Here we present results for HfSiON films that exhibit different trapping characteristics when exposed to ionizing radiation than either of these two previous types of dielectrics. Films with a high concentration of $\mathrm{Si}_{3} \mathrm{~N}_{4}$ exhibit significantly less radiation-induced charge trapping than the films discussed in the previous work.

Bias-temperature instability also is an important reliability concern for MOS devices. The applied bias at elevated temperatures induces interface traps and oxide trapped charges that affect the device threshold voltage and long term reliability [13]. Negative bias temperature instability (NBTI) is especially a concern for pMOS devices [14]. Previous experiments on $\mathrm{SiO}_{2}$ and $\mathrm{HfO}_{2}$ on Si MOS devices show positive interfacial and oxide charge generation [10], [11]. The mechanism for NBTI is still under debate [15]. However, a widely accepted model that is especially relevant for relatively low fields and thin oxides [13], [16] involves the release and movement of hydrogen species to the interface. The negative bias pulls $\mathrm{H}^{+}$into the bulk oxide, resulting in net positive charge in the oxide. Here we evaluate the differences in charge trapping of devices with homogeneous $\mathrm{HfSiON}$ films and ones that contain crystalline $\mathrm{HfO}_{2}$.

\section{DeVICE Details}

The devices considered in this study are MOS capacitors with aluminum front and back contacts, Hf Si oxynitride dielectrics, and p-type silicon substrates. The device cross section is shown schematically in Fig. 1. The devices were fabricated at North Carolina State University. The Hf/Ti source gases, $2 \% \mathrm{SiH}_{4}$ in $\mathrm{He}$, and $\mathrm{Hf}(\mathrm{IV}) / \mathrm{Ti}(\mathrm{IV}) t$-butoxide were deposited using remote plasma enhanced chemical vapor deposition (RPECVD). Two different Hf Si oxynitride pseudoternary alloys were integrated into these devices on nitrided, plasma-oxidized interfaces (e.g., $\mathrm{SiON}$ ). These $\mathrm{SiON}$ interfacial layers are $\sim 0.6 \mathrm{~nm}$. After deposition, rapid thermal annealing (RTA) for $\sim 1$ minute in $\mathrm{Ar}$ was performed at $900^{\circ} \mathrm{C}$. The samples were packaged in 28-pin dual inline packages at Georgia Tech. The dielectric constant $(k)$ for the low- $\mathrm{Si}_{3} \mathrm{~N}_{4}\left(\mathrm{Hf}_{0.6} \mathrm{SiO}_{0.2} \mathrm{~N}_{0.2}\right)$ and high-Si $\mathrm{N}_{4}$ $\left(\mathrm{Hf}_{0.3} \mathrm{SiO}_{0.4} \mathrm{~N}_{0.4}\right)$ content alloy films are $k=14.6$ and $k=$ 12.7 , respectively [17]. The low- $\mathrm{Si}_{3} \mathrm{~N}_{4}$ content film contains 


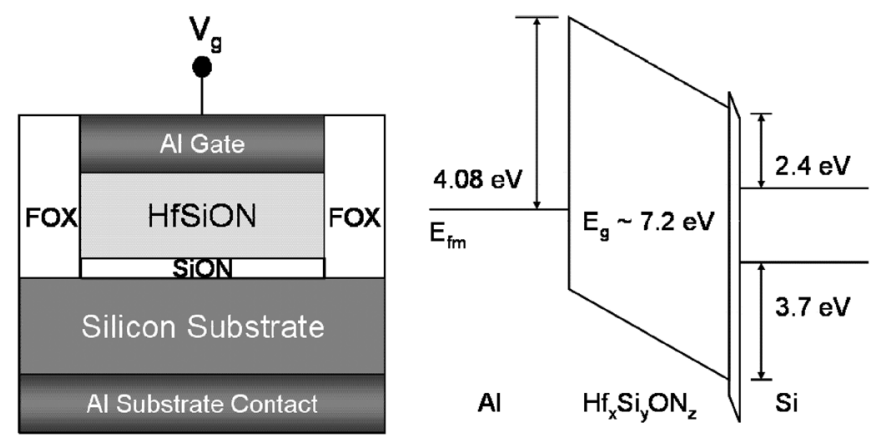

Fig. 1. Device structure and energy band schematic diagrams for Al/Hf$\mathrm{SiON} / \mathrm{Si} \mathrm{MOS}$ capacitors.

crystalline $\mathrm{HfO}_{2}$, while the high- $\mathrm{Si}_{3} \mathrm{~N}_{4}$ content film is homogeneous [17]. The devices in this study have physical oxide film thicknesses of $\sim 15 \mathrm{~nm}($ EOT $\sim 4 \mathrm{~nm})$ and $2 \mathrm{~nm}($ EOT $\sim 0.5 \mathrm{~nm})$.

\section{EXPERIMENTAL DETAILS}

Irradiation experiments were performed with an ARACOR $10-\mathrm{keV} \mathrm{X}$-ray source at a dose rate of $31.5 \mathrm{krad}\left(\mathrm{SiO}_{2}\right) / \mathrm{min}$. The devices were irradiated incrementally to $5 \operatorname{Mrad}\left(\mathrm{SiO}_{2}\right)$. For comparison of responses, nominally identical devices were electrically stressed for the same times required to reach each total dose increment. Bias temperature stress (BTS) experiments were done on the packaged samples in a Delta Design 9039 oven. An Agilent 4156 B Semiconductor Parameter Analyzer was used to apply biases and to monitor the currents during the experiments.

Devices were characterized via $1 \mathrm{MHz}$ capacitance-voltage $(C V)$ measurements at sweep rates from 0.02 to $0.05 \mathrm{~V} / \mathrm{s}$ using the midgap method of Winokur et al. [18]. $C V$ measurements were swept from accumulation to inversion after each stress interval or total dose. We note that there is a transitional period between the stress/radiation and measurement, during which no bias is applied. A fraction of the trapped charges may recombine and/or detrap during this time. High-k dielectrics are especially susceptible to electron trapping/detrapping [19]. Conventional DC measurement techniques may not account for the trapped electrons that are quickly discharged after the stress is released. A detailed study of the stress-induced threshold voltage instabilities in high-k dielectrics requires transient measurement techniques such as the pulse current-voltage $I-V$ characterization [20]. Nevertheless conventional $C V$ and $I-V$ characterization methods are adequate for the total dose irradiation analysis of high-k devices. A large number of devices were used for the irradiation and stress experiments. Each data set represents results from at least 5 devices that showed similar responses.

\section{RESULTS AND DISCUSSION}

\section{A. Pre-Irradiation Characterization}

The pre-irradiation $C V$ characteristics showed considerable hysteresis in the thicker devices $\left(\Delta V_{\mathrm{mg}} \sim 200 \mathrm{mV}\right.$ and $150 \mathrm{mV}$ for the low- and high-Si ${ }_{3} \mathrm{~N}_{4}$ films, respectively). The hysteresis for a $15 \mathrm{~nm}$ low- $\mathrm{Si}_{3} \mathrm{~N}_{4}$ content device is shown in Fig. 2. The hysteresis indicates a relatively high density of process-induced border traps [21]. The effective border trap density, $\Delta N_{\mathrm{bt}}$, can

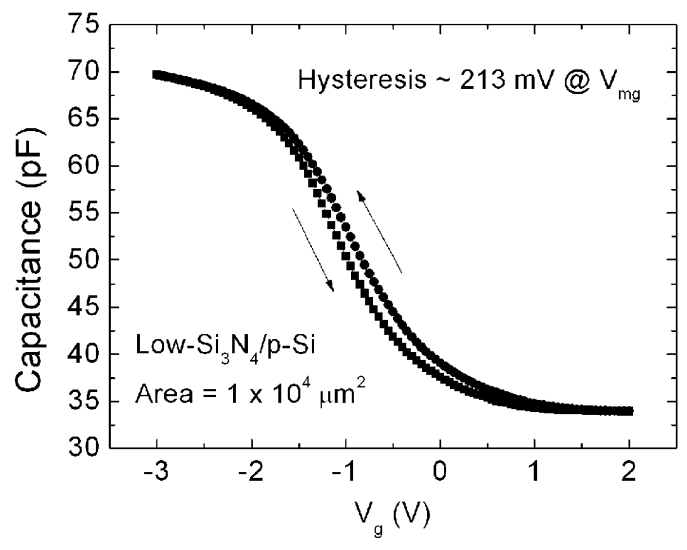

Fig. 2. 1-MHz capacitance-voltage characteristics for a $15-\mathrm{nm}$ low- $\mathrm{Si}_{3} \mathrm{~N}_{3}$ $\left(\mathrm{Hf}_{0.6} \mathrm{Si}_{0.2} \mathrm{ON}_{0.2}\right)$ film p-substrate MOS capacitor swept from accumulation to inversion and inversion to accumulation. The hysteresis is $213 \mathrm{mV}$ at midgap.

be calculated by integrating the difference in forward and reverse $\mathrm{C}-\mathrm{V}$ curves [22]

$$
\Delta N_{\mathrm{bt}} \sim(1 / \mathrm{qA}) \int\left|\mathrm{C}_{r}-\mathrm{C}_{f}\right| \mathrm{dV}
$$

Here- $\mathrm{q}$ is the electron charge, $\mathrm{A}$ is the capacitor area, and $\mathrm{C}_{\mathrm{r}}$ and $\mathrm{C}_{\mathrm{f}}$ are the reverse and forward capacitance values. The estimated $\Delta N_{\text {bt }}$ values are $\sim 2.7 \times 10^{11} \mathrm{~cm}^{-2}$ and $3.3 \times 10^{11} \mathrm{~cm}^{-2}$ for the high- and low- $\mathrm{Si}_{3} \mathrm{~N}_{4}$ devices respectively. There is no measurable hysteresis in the $2 \mathrm{~nm}$ devices.

There is also significant pre-irradiation interface trap charge density $\left(N_{\text {it }} \sim 4 \times 10^{12} \mathrm{~cm}^{-2}\right)$ in the 15 and $13 \mathrm{~nm}$ gate oxide devices. The pre-irradiation $N_{\text {it }}$ is much smaller $\left(N_{\text {it }} \sim 5 \times\right.$ $10^{11} \mathrm{~cm}^{-2}$ ) in the $2 \mathrm{~nm}$ devices.

Fig. 3 illustrates the gate leakage current densities at $V_{\mathrm{fb}}+1 \mathrm{~V}$ for the low- and high- $\mathrm{Si}_{3} \mathrm{~N}_{4}$ devices of various film thicknesses. The gate leakage for films of EOT $=2 \mathrm{~nm}$ is approximately 5 orders of magnitude less than in $\mathrm{SiO}_{2}$ devices of equivalent electrical thickness. This demonstrates the main advantage of these devices relative to $\mathrm{SiO}_{2}$ devices. Also, the low- and high-Si ${ }_{3} \mathrm{~N}_{4}$ films exhibit similar levels of gate leakage current for the thicker oxide devices. However, the low- $\mathrm{Si}_{3} \mathrm{~N}_{4}$ film shows slightly higher leakage for thinner films. The higher density of defect states in the low- $\mathrm{Si}_{3} \mathrm{~N}_{4}$ devices produces higher trap-assisted tunneling current [23], which is more significant in the thinner oxide devices.

\section{B. X-ray Irradiation}

Neither the hysteresis nor the gate leakage current changes significantly with irradiation. Fig. 4 shows the $C V$ characteristics of the $15 \mathrm{~nm}$ low- $\mathrm{Si}_{3} \mathrm{~N}_{4}$ device with irradiation bias $V_{g}=$ $0 \mathrm{~V}$. The flatband voltage shifts $\left(\Delta V_{\mathrm{fb}}\right)$ and midgap voltage shifts $\left(\Delta V_{\mathrm{mg}}\right)$ were nearly identical for all bias conditions and all devices. Thus, radiation-induced changes in the $C V$ characteristics were predominantly due to radiation-induced oxidetrapped charge. The lack of significant change in interface trap density with irradiation most likely is due to the large pre-irradiation interface trap density in the 13 and $15 \mathrm{~nm}$ gate oxide devices. 


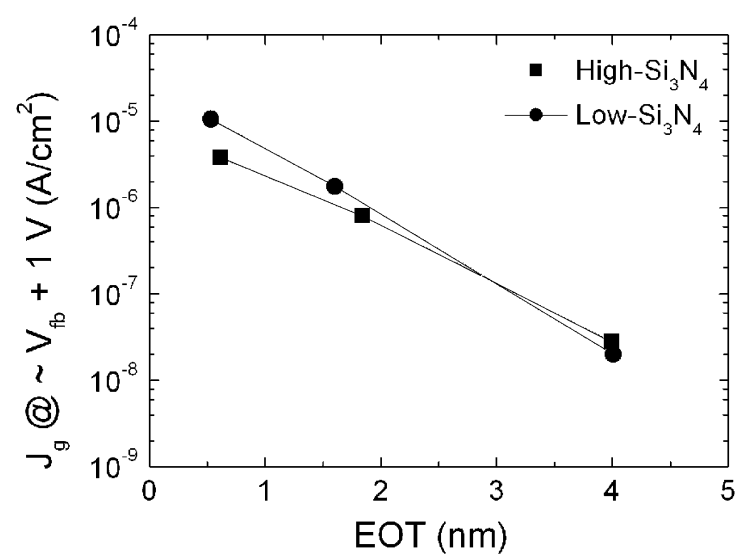

Fig. 3. Gate leakage current density $\left(\mathrm{J}_{\mathrm{g}}\right)$ at $\mathrm{V}_{\mathrm{fb}}+1 \mathrm{~V}$ for low- and high-Si $\mathrm{N}_{3} \mathrm{~N}_{4}$ HfSiON devices with physical film thicknesses 15,6 , and $2 \mathrm{~nm}$.

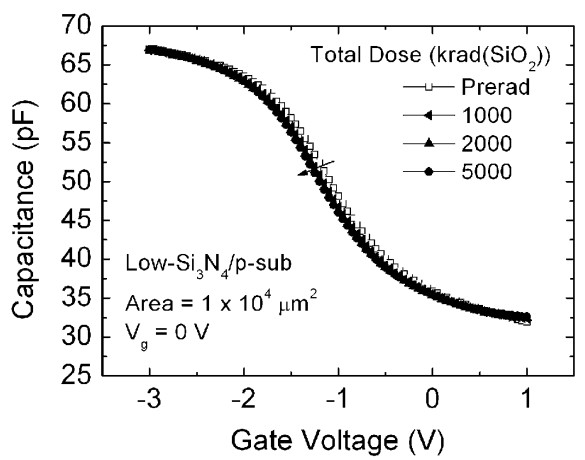

Fig. 4. 1-MHz capacitance-voltage characteristics for a p-substrate low- $\mathrm{Si}_{3} \mathrm{~N}_{3}$ $\left(\mathrm{Hf}_{0.6} \mathrm{Si}_{0.2} \mathrm{ON}_{0.2}\right)$ film MOS capacitor irradiated with $\mathrm{V}_{\mathrm{g}}=0 \mathrm{~V}$ to $5000 \mathrm{krad}\left(\mathrm{SiO}_{2}\right)$

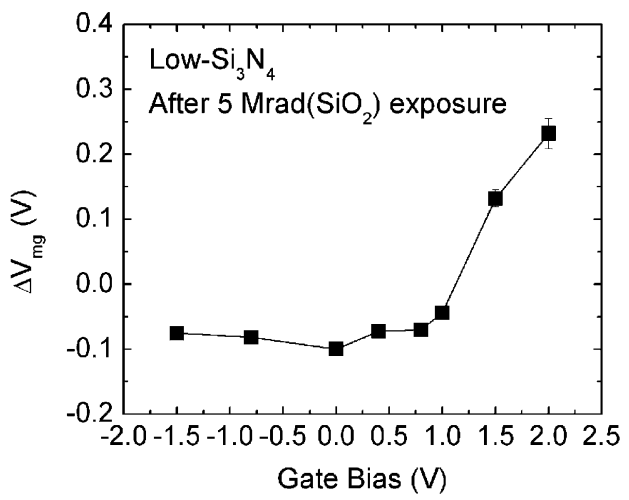

Fig. 5. $\Delta V_{\mathrm{mg}}$ as a function of gate bias during irradiation for $15 \mathrm{~nm}$ low- $-\mathrm{Si}_{3} \mathrm{~N}_{4}$ $\left(\mathrm{Hf}_{0.6} \mathrm{Si}_{0.2} \mathrm{ON}_{0.2}\right) \mathrm{Si}$ MOS devices irradiated to $5 \mathrm{Mrad}\left(\mathrm{SiO}_{2}\right)$.

Fig. 5 shows $\Delta V_{\mathrm{mg}}$ as a function of dose for the $15 \mathrm{~nm}$ low- $\mathrm{Si}_{3} \mathrm{~N}_{4}$ devices irradiated to $5 \mathrm{Mrad}\left(\mathrm{SiO}_{2}\right)$ under various bias conditions. We observe similar changes in $\Delta V_{\mathrm{mg}}$ for gate biases ranging from -1.5 to $1 \mathrm{~V}$, with larger positive shifts occurring for gate biases of 1.5 and $2 \mathrm{~V}$. The lack of significant bias dependence at moderate gate biases suggests a relatively uniform distribution of bulk charge traps, similar to previous work on hafnium silicate films [8]. The charge centroid is not affected significantly at low electric fields due to the low mobility of holes in hafnium silicate and/or high bulk oxide-trap density [24]. The similar levels of $\Delta V_{\mathrm{mg}}$ for devices irradiated

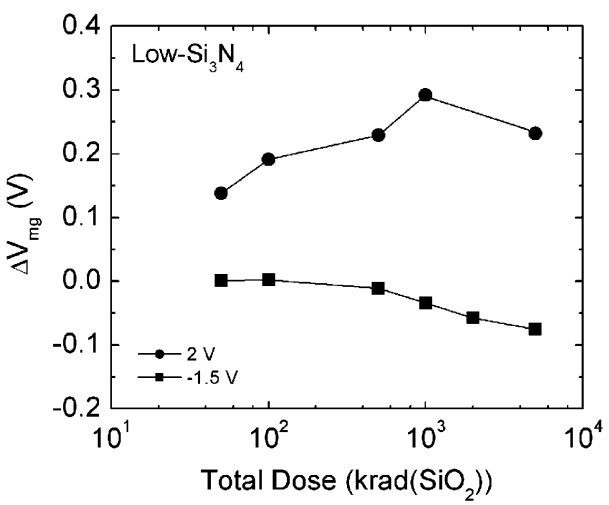

Fig. 6. $\Delta V_{\mathrm{mg}}$ versus total dose for $15 \mathrm{~nm} \mathrm{low}-\mathrm{Si}_{3} \mathrm{~N}_{4}\left(\mathrm{Hf}_{0.6} \mathrm{Si}_{0.2} \mathrm{ON}_{0.2}\right) \mathrm{Si}$ MOS devices irradiated to $5 \mathrm{Mrad}\left(\mathrm{SiO}_{2}\right)$, with $V_{g}=2$ and $-1.5 \mathrm{~V}$ during irradiation.

with different biases may also be the consequence of a balance of electron and hole trapping in these nitrided $\mathrm{Hf}$ silicates. Previous work has shown that $\mathrm{HfO}_{2}$ dielectric films are more susceptible to electron trapping than $\mathrm{SiO}_{2}$ due to the large pre-irradiation bulk trap density [12]. Also, nitrided $\mathrm{SiO}_{2}$ is known to contain both electron and hole traps [25], [26].

The exceptions to the lack of bias dependence occur only at higher positive bias conditions ( 1.5 and $2 \mathrm{~V}$ ). Fig. 6 shows $\Delta V_{\mathrm{mg}}$ versus total dose for positive and negative bias conditions. The value of $\Delta V_{\mathrm{mg}}$ decreases monotonically for the negatively biased device, indicating net positive charge in the oxide. In contrast, the positively biased device shows primarily electron trapping, although the turnaround at higher doses shows that the net positive shift reflects an increasing amount of hole trapping relative to electron trapping at the highest doses.

At the higher positive voltages during irradiation, the Si surface layer is in inversion, and significant electron tunneling occurs. Constant voltage stress (CVS) experiments revealed that electron injection during irradiation causes significant amounts of electron trapping at the higher dose levels, due to the additional time under bias for these (but not lower) bias conditions. As we show below, the net electron trapping in Fig. 6 under large positive bias is a combination of electron injection and radiation-induced charge trapping. These combined effects are increasingly important in thin high-k dielectric layers [9], [12].

Figs. 7 and 8 compare the total-dose responses of the low- and high-Si $\mathrm{N}_{4}$ films with positive and negative irradiation biases. The radiation responses of the films are similar for the negative bias case; the low- $\mathrm{Si}_{3} \mathrm{~N}_{4}$ films show slightly enhanced levels of charge trapping relative to the high- $\mathrm{Si}_{3} \mathrm{~N}_{4}$ film. However, the positively biased devices behaved differently: the high-Si ${ }_{3} \mathrm{~N}_{4}$ film did not exhibit significant levels of electron trapping after irradiation, so the midgap voltage shift was negative due to net positive charge trapping.

\section{Constant Voltage Stress}

As demonstrated from the irradiation results, a significant amount of electron trapping occurs in the low- $\mathrm{Si}_{3} \mathrm{~N}_{4}$ films only at relatively high positive gate biases during irradiation. CVS tests show that the positive gate bias induces considerable electron trapping via electron injection from the substrate. Fig. 9 


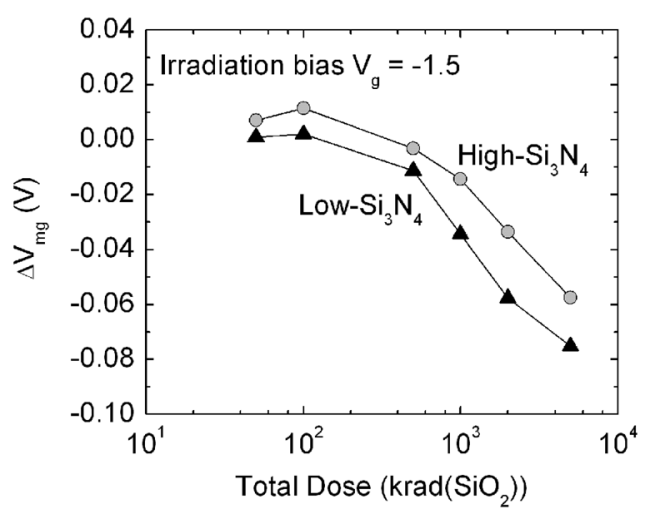

Fig. 7. $\Delta V_{\mathrm{mg}}$ versus total dose for $15 \mathrm{~nm}$ low- $\mathrm{Si}_{3} \mathrm{~N}_{4}\left(\mathrm{Hf}_{0.6} \mathrm{Si}_{0.2} \mathrm{ON}_{0.2}\right)$ and $13 \mathrm{~nm}$ high- $\mathrm{Si}_{3} \mathrm{~N}_{4}\left(\mathrm{Hf}_{0.3} \mathrm{Si}_{0.4} \mathrm{ON}_{0.4}\right) \mathrm{Si}$ MOS devices irradiated to $5 \mathrm{Mrad}\left(\mathrm{SiO}_{2}\right)$ with $V_{g}=-1.5 \mathrm{~V}$.

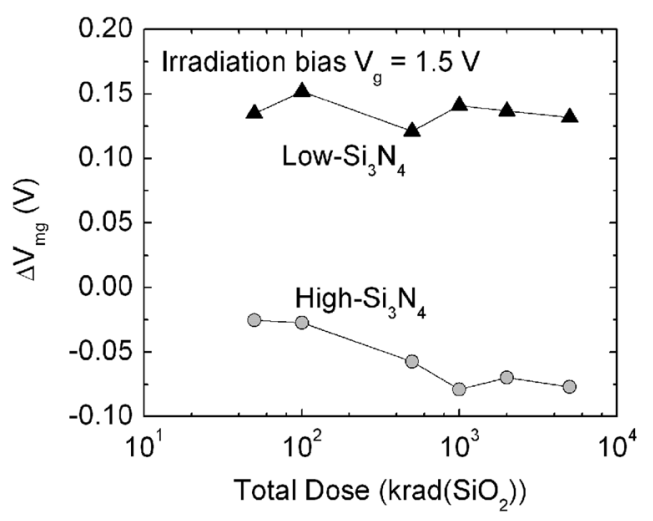

Fig. 8. $\Delta V_{\mathrm{mg}}$ versus total dose for $15 \mathrm{~nm}$ low- $\mathrm{Si}_{3} \mathrm{~N}_{4}\left(\mathrm{Hf}_{0.6} \mathrm{Si}_{0.2} \mathrm{ON}_{0.2}\right)$ and $13 \mathrm{~nm}$ high- $\mathrm{Si}_{3} \mathrm{~N}_{4}\left(\mathrm{Hf}_{0.3} \mathrm{Si}_{0.4} \mathrm{ON}_{0.4}\right) \mathrm{Si}$ MOS devices irradiated to $5 \mathrm{Mrad}\left(\mathrm{SiO}_{2}\right)$ with $\mathrm{V}_{\mathrm{g}}=1.5 \mathrm{~V}$.

shows $\Delta V_{\mathrm{mg}}$ for the low- $\mathrm{Si}_{3} \mathrm{~N}_{4}$ film stressed with various positive biases for times similar to irradiation times. Clearly, the amount of electron trapping is larger for higher stress voltages. In addition, the initial increase in $\Delta V_{\mathrm{mg}}$ makes up the majority of the total shift, consistent with the positive bias irradiation results. The sudden increase in $\Delta V_{\mathrm{mg}}$ after the initial stress interval of $\sim 100 \mathrm{~s}$ is followed by more gradual increases with stress time. This may be due to the presence of a higher density of defects near the high-k/Si interface. The HfSiON/Si MOS structure contains a thin interfacial layer of SiON between the high-k film and Si substrate. High densities of defects such as $\mathrm{O}$ vacancies are ideal trap sites for electrons/holes in these nitride-rich oxynitride layers [27], [28]. Electrons fill these traps before reaching the trap sites located deeper in the bulk oxide. The band diagram in Fig. 10 illustrates the electron trapping from substrate injection under positive gate bias. Negative gate voltages did not cause hole injection since the barrier height for hole tunneling is higher than for electrons. The valence band offset for $\mathrm{HfSiON}$ and $\mathrm{Si}$ is $\sim 3.7 \mathrm{eV}$, whereas the conduction band offset is $\sim 2.4 \mathrm{eV}$.

Fig. 11 demonstrates the CVS data of the high- and low- $\mathrm{Si}_{3} \mathrm{~N}_{4}$ devices stressed for times varying from 1 to $10^{5}$ seconds. We observe large initial $\Delta V_{\mathrm{mg}}$ even after $1 \mathrm{~s}$. There is also a large increase in $\Delta V_{\mathrm{mg}}$ after $10^{4} \mathrm{~s}$, as the injected electrons fill the bulk oxide traps. These results are consistent

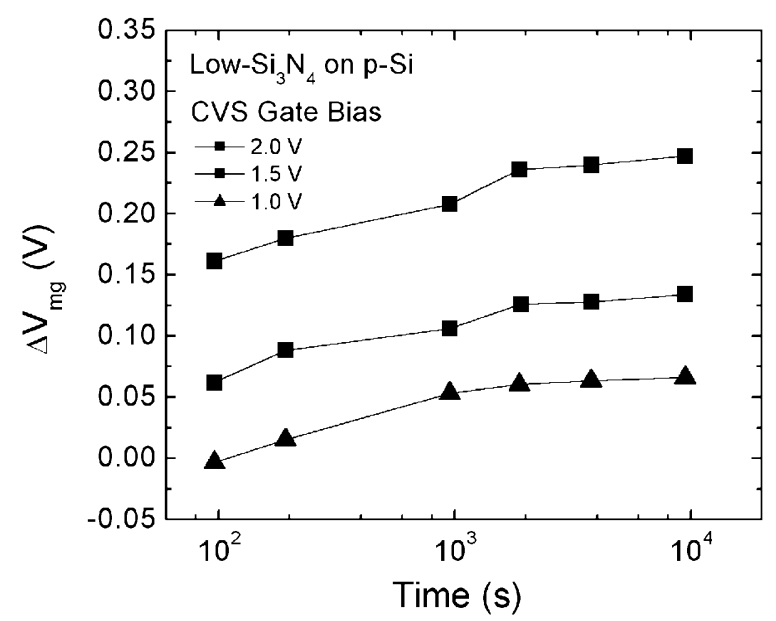

Fig. 9. $\Delta V_{\mathrm{mg}}$ versus stress time for $15 \mathrm{~nm} \mathrm{low}-\mathrm{Si}_{3} \mathrm{~N}_{4}\left(\mathrm{Hf}_{0.6} \mathrm{Si}_{0.2} \mathrm{ON}_{0.2}\right) \mathrm{Si}$ MOS devices stressed with $\mathrm{V}_{\mathrm{g}}=1,1.5$, and $2 \mathrm{~V}$ at room temperature.

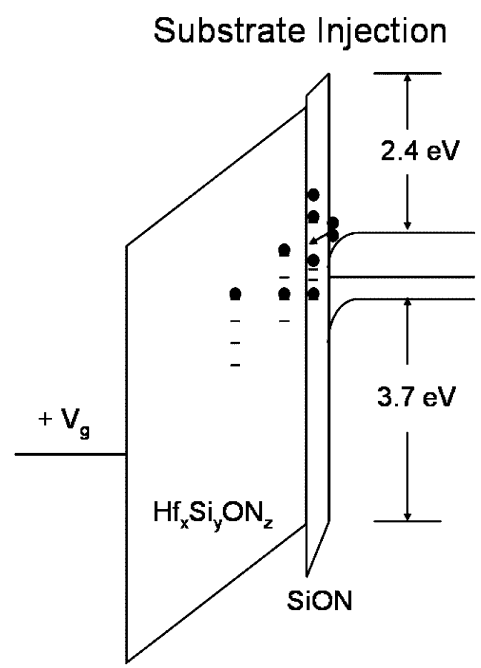

Fig. 10. Energy band diagram illustrating substrate electron injection for a p-substrate device under positive gate bias.

with the injected electrons filling the traps near the oxynitride interfacial layer before reaching the bulk oxide traps.

Additionally the $C V$ characteristics showed no significant change in interface trap densities after CVS. This result differs from previous work on p-substrate $\mathrm{HfO}_{2}$ capacitors that showed significant interface trap formation after CVS [12]. However the $\mathrm{HfO}_{2}$ devices in that work had much lower pre-irradiation interface trap charge density $\left(N_{\text {it }}<1 \times 10^{11} \mathrm{~cm}^{-2}\right)$ than the devices here [12]. The nitride layers prevent $\mathrm{H}$ diffusion into the interfacial transition regions, thereby inhibiting interface trap formation; however, this may also limit one's ability to passivate $\mathrm{Si}$ dangling bonds at the interface during processing [3], [29].

The differences in the chemical structures of the two films evidently cause the differences in the radiation and CVS results. The "The low- $\mathrm{Si}_{3} \mathrm{~N}_{4}$ content film chemically phase separates after $900^{\circ} \mathrm{C}$ annealing, containing crystalline $\mathrm{HfO}_{2}$ and noncrystalline $\mathrm{SiO}_{2}$ [17]. Crystalline $\mathrm{HfO}_{2}$ contains grain boundaries that behave as electron trap sites [24]. The increased electron trapping in crystalline $\mathrm{HfO}_{2}$ is primarily associated with $\mathrm{O}$ vacancies, which are clustered at internal grain boundaries 


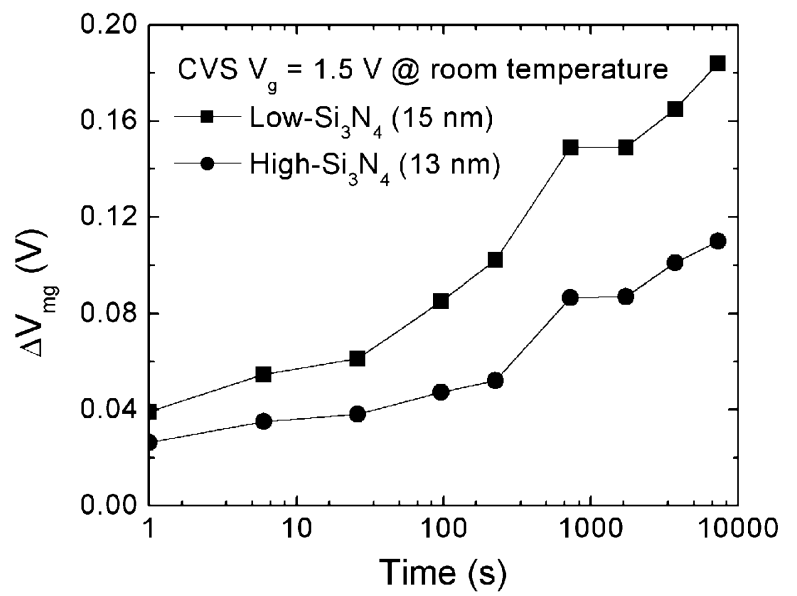

Fig. 11. $\Delta V_{\mathrm{mg}}$ versus stress time for $15 \mathrm{~nm}$ low- $\mathrm{Si}_{3} \mathrm{~N}_{4}\left(\mathrm{Hf}_{0.6} \mathrm{Si}_{0.2} \mathrm{ON}_{0.2}\right)$ and $13 \mathrm{~nm}$ high-Si $\mathrm{N}_{4}\left(\mathrm{Hf}_{0.3} \mathrm{Si}_{0.4} \mathrm{ON}_{0.4}\right) \mathrm{Si}$ MOS devices with $\mathrm{V}_{\mathrm{g}}=1.5 \mathrm{~V}$ during constant voltage stress at room temperature.

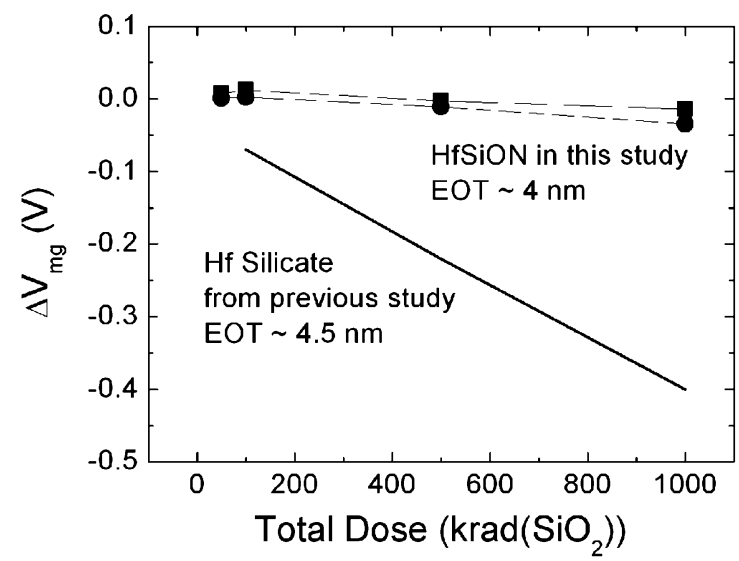

Fig. 12. $\Delta V_{\mathrm{mg}}$ versus total dose for the $\mathrm{HfSiON}$ devices $(\mathrm{EOT}=4 \mathrm{~nm})$ in this report and $\mathrm{Hf}$ silicate devices from a previous study [12] $(\mathrm{EOT}=4.5 \mathrm{~nm})$ with the same capacitor areas.

[27]. Conversely, the high- $\mathrm{Si}_{3} \mathrm{~N}_{4}$ content film remains non-crystalline after the $900^{\circ} \mathrm{C}$ anneal and contains fewer trap sites due to the absence of grain boundary defects. The reduced defect generation rate under X-ray irradiation is similar to $\mathrm{SiO}_{2}$, consistent with a chemical self-organization that minimizes percolation of bond-strain preventing chemical phase separation [17]. Thus, the high- $\mathrm{Si}_{3} \mathrm{~N}_{4}$ content film exhibits reduced charge trapping even at high positive bias conditions.

\section{Comparison With HF Silicate}

Fig. 12 compares the worst-case irradiation results for the Hf$\mathrm{SiON}$ devices in this study with Hf silicate devices from a previous study [8]. The $\Delta V_{\mathrm{mg}}$ curves of the $\mathrm{Hf}$ silicate devices in Fig. 12 are linear fits from data reported in [8]. They have similar dimensions (area $=1 \times 10^{-4} \mathrm{~cm}^{2}$ and EOT $=4.5 \mathrm{~nm}$ ) as the devices in this work. The Hf silicate devices also had a high pre-irradiation interface trap density $\left(N_{\text {it }} \sim 2 \times 10^{12} \mathrm{~cm}^{-2}\right)$. They displayed large $C V$ hysteresis ( $>100 \mathrm{mV}$ ) after baking at $150^{\circ} \mathrm{C}$ [8]. These similar qualities allow for a fair comparison of their radiation responses.
The radiation-induced net oxide-charge densities $\left(\Delta N_{\text {ot }}\right)$ as projected to the $\mathrm{Si} / \mathrm{SiO}_{2}$ interface were estimated from [28]:

$$
\Delta N \text { ot }=-\frac{C o x \Delta V \mathrm{mg}}{q A}
$$

where $\Delta N_{\text {ot }}$ is the change in oxide-trap charge density, $C_{\text {ox }}$ is the oxide capacitance, $-q$ is the electron charge, and $A$ is the capacitor area. After exposure to a total dose of $1000 \mathrm{krad}\left(\mathrm{SiO}_{2}\right)$ with $V_{g}=-1.5 \mathrm{~V}, \Delta N_{\mathrm{ot}}=7.7 \times 10^{10} \mathrm{~cm}^{-2}$ and $2.1 \times$ $10^{11} \mathrm{~cm}^{-2}$ for the high- and low-Si ${ }_{3} \mathrm{~N}_{4}$ content devices, respectively, while $\Delta N_{\mathrm{ot}}=1.2 \times 10^{12} \mathrm{~cm}^{-2}$ for the Hf silicate devices [8]. Hence, the amorphous high- $\mathrm{Si}_{3} \mathrm{~N}_{4}$ film displays $\sim 16 \times$ less $\Delta N_{\text {ot }}$ relative to the Hf silicate devices in [8]. With the exception of electron trapping at the highest applied electric fields, the low- $\mathrm{Si}_{3} \mathrm{~N}_{4}$ content film still demonstrates improved charge trapping characteristics relative to the Hf silicate films, with $\Delta N_{\text {ot }} \sim 5.7 \times$ less, despite the presence of nano-crystalline $\mathrm{HfO}_{2}$ grains. The high-Si $\mathrm{N}_{3}$ content film is similar to an $\mathrm{Hf}$ silicate film due to its amorphous structure. However, the improvement exhibited by the low- $\mathrm{Si}_{3} \mathrm{~N}_{4}$ content films relative to the $\mathrm{Hf}$ silicate films is noteworthy, since crystalline $\mathrm{HfO}_{2}$ has higher defect density and greater charge trapping than high quality Hf silicates [27]

The large pre-irradiation interface-trap density likely influences the irradiation results in both the HfSiON devices here and the Hf silicate devices from [8]. The effects of the high pre-irradiation $N_{\mathrm{it}}$ are similar to the saturation of interface traps at higher doses in $\mathrm{SiO}_{2}$ due to the exhaustion of precursor defects [28]. Nevertheless the sizeable reduction in the radiation-induced net oxide-trap charge indicates the advancement in fabrication processes of $\mathrm{Hf}$ alloy MOS devices since 2002, when results for an earlier generation of Hf silicate devices were reported [8]. The results indicate the promise of nitrided Hf silicates for potential future use in radiation environments.

\section{E. Bias-Temperature Stress}

We further investigate the reliability of these films with biastemperature stress experiments. The $2 \mathrm{~nm}$ films displayed larger shifts in midgap voltage relative to the thicker films. Therefore, the following discussion focuses on results of these thinner films. Bias-temperature stress tests were performed on n-type substrate devices with applied gate biases ranging from -2 to $2 \mathrm{~V}(\sim-11$ to $9 \mathrm{MV} / \mathrm{cm})$. The oxides break down quickly for positive biases $>1 \mathrm{~V}$. Fig. 13 illustrates $\Delta V_{\mathrm{mg}}$ as a function of stress temperature for both types of film compositions. Both types of films exhibited electron trapping under negative bias-temperature stress (NBTS) and hole trapping under positive bias-temperature stress (PBTS).

The NBTI results are unlike behavior typically found in thin $\mathrm{HfO}_{2}$ devices, where positive interface and oxide trapped charge generation dominate [10], [11]. NBTS induces electron trapping that is likely caused by electron injection from the gate for the devices in this report. The electric fields applied during NBTS here are significantly higher than the values used in previous experiments on $\mathrm{HfO}_{2} / \mathrm{SiON}$ devices that produced negative shifts in $\Delta V_{\mathrm{mg}}$, where $V_{g}$ varied from $\pm 1-3 \mathrm{MV} / \mathrm{cm}$ [10], [11]. However we found no measurable change in $\Delta V_{\mathrm{mg}}$ for smaller values of gate bias. Moreover CVS performed at room temperature with similar gate biases and stress times as in the NBTS tests 


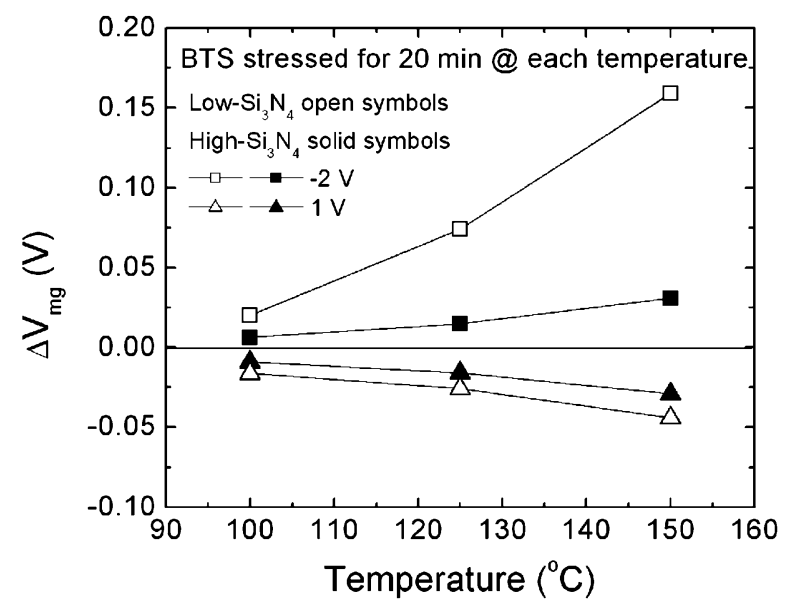

Fig. 13. $\Delta V_{\mathrm{mg}}$ versus stress temperature for $2 \mathrm{~nm} \quad$ low- $\mathrm{Si}_{3} \mathrm{~N}_{4}$ $\left(\mathrm{Hf}_{0.6} \mathrm{Si}_{0.2} \mathrm{ON}_{0.2}\right)$ and high- $\mathrm{Si}_{3} \mathrm{~N}_{4}\left(\mathrm{Hf}_{0.3} \mathrm{Si}_{0.4} \mathrm{ON}_{0.4}\right) \mathrm{Si}$ MOS devices with BTS bias $\mathrm{V}_{g}=-2$ and $1 \mathrm{~V}$. Each device was stressed for $20 \mathrm{~min}$ at each temperature. $\mathrm{C}-\mathrm{V}$ characteristics were measured after each stress interval when the device returned to room temperature.

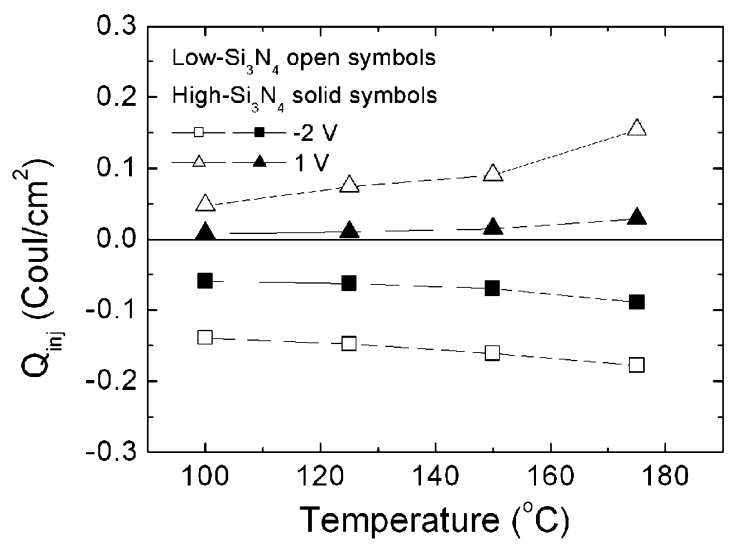

Fig. 14. $\mathrm{Q}_{\mathrm{inj}}$ as a function of temperature for the low- and high- $\mathrm{Si}_{3} \mathrm{~N}_{4}$ devices with BTS bias $V_{g}=-2$ and $1 \mathrm{~V}$. The $Q_{\text {inj }}$ represents injected charge after 20 min stress at each temperature.

produced negligible change in $\Delta V_{\mathrm{mg}}$ (not shown here). Therefore the amount of charge trapping depends strongly on temperature.

The amount of charge trapping depends on how much charge is injected during the stress. The gate injection current is likely caused by Fowler-Nordheim (F-N) and trap-assisted tunneling. The F-N current results in electron trapping via gate injection in $\mathrm{SiO}_{2}$-based MOS capacitors at high electric fields $(>6$ $\mathrm{MV} / \mathrm{cm}$ ) [31]. Studies also show that the F-N emission rate increases with increasing temperature (in the range of $25-400^{\circ} \mathrm{C}$ ) [32]. Fig. 14 illustrates the injected charge from each temperature stress for the HfSiON devices. We observe increasing charge injection with increasing temperature. Fig. 15 shows the F-N plot for a $2 \mathrm{~nm}$ low- $\mathrm{Si}_{3} \mathrm{~N}_{4}$ content device at room temperature and at $150^{\circ} \mathrm{C}$. The devices exhibit F-N tunneling at the higher gate biases (approaching $-2 \mathrm{~V}$ ). The higher magnitude of the curve for the device at $150^{\circ} \mathrm{C}$ also indicates the higher $\mathrm{F}-\mathrm{N}$ emission rate at elevated temperature.

The enhanced levels of charge trapping and current levels observed in the low- $\mathrm{Si}_{3} \mathrm{~N}_{4}$ film, which contains more defect states than the high- $\mathrm{Si}_{3} \mathrm{~N}_{4}$ film, also suggest that trap-assisted

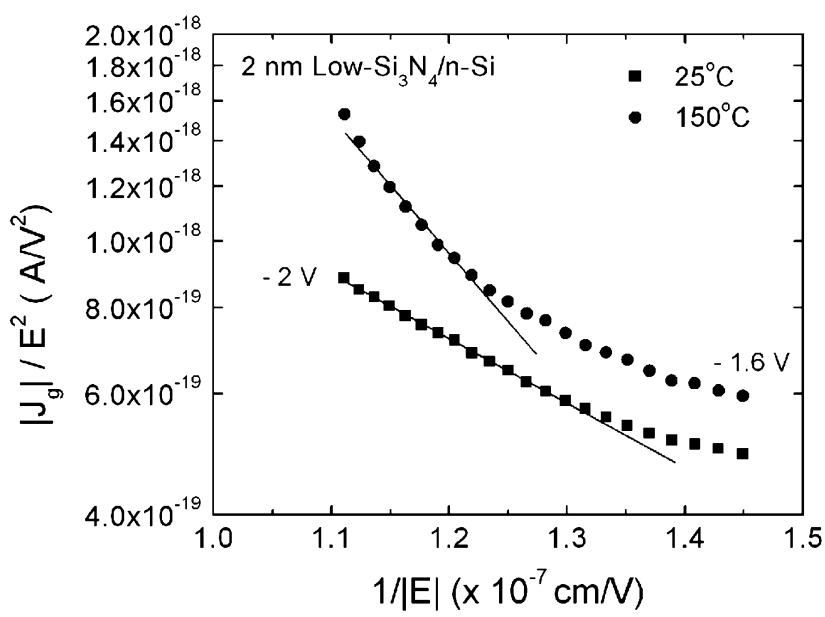

Fig. 15. $\left|\mathrm{J}_{\mathrm{g}}\right| / \mathrm{E}^{2}$ versus $1 /|\mathrm{E}|$ for a $2 \mathrm{~nm}$ low-Si ${ }_{3} \mathrm{~N}_{4} / \mathrm{n}-\mathrm{Si}$ device at room temperature and $150^{\circ} \mathrm{C}$.

tunneling is an additional mechanism for the charge trapping. Trap-assisted tunneling contributes to the total leakage current in high-k dielectrics more substantially than in $\mathrm{SiO}_{2}$ due to the higher density of post-process defect states in high-k materials [23].

The results indicate that these $\mathrm{HfSiON} / \mathrm{Si}$ devices are less sensitive to bias temperature stress than previous $\mathrm{HfO}_{2}$ devices [10]-[12]. Very large electric fields that exceed typical operating voltages are required to cause charge injection from the gate. While the charge trapping depends strongly on temperature, the sources of bias-temperature stress degradation observed here are different than typical NBTI mechanisms. Unlike the $\mathrm{HfO}_{2}$ devices in [10]-[12], the HfSiON devices in this study were not treated with a hydrogen-containing (e.g., forming gas) anneal, which is reflected by the larger post-process interface trap density $\left(N_{\text {it }} \sim 5 \times 10^{11} \mathrm{~cm}^{-2}\right)$ for the devices used here. Because NBTI is sensitive to hydrogen [10]-[16], this may account for at least some of the difference in response. The challenge in device processing is to introduce enough hydrogen to passivate the dangling bonds at the interface, without introducing so much that one sees radiation-induced interface-trap buildup and NBTI [10]-[16].

\section{CONCLUSION}

We have examined the total-dose irradiation response of lowand high- $\mathrm{Si}_{3} \mathrm{~N}_{4}$ content $\mathrm{Hf} \mathrm{Si}$ oxynitride on $\mathrm{Si}$ MOS devices. We found significant electron trapping in the low- $\mathrm{Si}_{3} \mathrm{~N}_{4}$ content devices, but the high- $\mathrm{Si}_{3} \mathrm{~N}_{4}$ content devices exhibited relatively little electron trapping. CVS experiments showed that positive bias caused considerable electron injection (from the substrate), especially in the low- $\mathrm{Si}_{3} \mathrm{~N}_{4}$ content devices. Furthermore, by comparing the radiation response and CVS results of the low- and high- $\mathrm{Si}_{3} \mathrm{~N}_{4}$ content devices, we conclude that electron trap sites originate from the grain boundary-induced defect states in the $\mathrm{HfO}_{2}$ nano-grains in the chemically phase-separated low- $\mathrm{Si}_{3} \mathrm{~N}_{4}$ film. Both types of devices showed considerable reduction in total-dose-induced net oxide charge relative to Hf silicate devices, with $\Delta N_{\text {ot }}$ approximately $16 \times$ less for the high- $\mathrm{Si}_{3} \mathrm{~N}_{4}$ content device after $1 \mathrm{Mrad}\left(\mathrm{SiO}_{2}\right)$ exposure.

High electric fields $(-11$ and $4 \mathrm{MV} / \mathrm{cm})$ were required to induce electron/hole trapping via gate injection. Furthermore, the 
charge trapping only occurred for stress at elevated temperatures $\left(100-175^{\circ} \mathrm{C}\right)$. Consistently, the charge injection increases with increasing temperature. Low-Si $\mathrm{N}_{4}$ content devices exhibit enhanced degradation from bias-temperature stress relative to the high- $\mathrm{Si}_{3} \mathrm{~N}_{4}$ content devices. Both types of HfSiON films exhibit improved radiation hardness relative to previous Hf silicate devices [8]. They also show improvement in bias-temperature reliability with respect to $\mathrm{HfO}_{2}$ based devices [10]-[12]. However the reduced instability possibly comes at the expense of higher post-process $N_{\text {it }}$. Thus with further improvements to reduce the post-process interstate densities, $\mathrm{HfSiON}$ is a promising alternative to $\mathrm{SiO}_{2}$ as the gate dielectric in advanced MOS devices.

\section{ACKNOWLEDGMENT}

The authors would like to thank Prof. L. Feldman and Prof. S. Pantelides for insightful discussions, and D. Loveless for his assistance in designing the test board.

\section{REFERENCES}

[1] G. Ribes, J. Mitard, M. Denais, S. Bruyere, F. Monsieur, C. Parthasarathy, E. Vincent, and G. Ghibaudo, "Review on high-k dielectrics reliability issues," IEEE Trans. Dev. Mater. Reliab., vol. 5, no. 1, pp. 5-19, Mar. 2005.

[2] P. Punchaipetch, T. Okamoto, H. Nakamura, Y. Uraoka, T. Fuyuki, and S. Horii, "Effect of nitrogen on electrical and physical properties of polyatomic layer chemical vapor deposition $\mathrm{HfSi}_{\mathrm{x}} \mathrm{O}_{\mathrm{y}}$ gate dielectrics," Jpn. J. Appl. Phys., vol. 43, pp. 7815-7820, 2004.

[3] M. Saitoh, M. Terai, N. Ikarashi, H. Watanabe, S. Fujieda, T. Iwamoto, T. Ogura, A. Morioka, K. Watanabe, T. Tatsumi, and H. Watanabe, "1.2 nm HfSiON/SiON stacked gate insulators for 65-nm-node MISFETs," Jpn. J. Appl. Phys., vol. 44, pp. 2330-2335, 2005.

[4] S. Sayan, N. V. Nguyen, J. Ehrstein, J. J. Chambers, M. R. Visokay, M. A. Quevedo-Lopez, L. Colombo, D. Yoder, I. Levin, D. A. Fischer, M. Paunescu, O. Celik, and E. Garfunkel, "Effect of nitrogen on band alignment in HfSiON gate dielectrics," Appl. Phys. Lett., vol. 87, 2005, article no. 212905.

[5] M. R. Visokay, J. J. Chamber, A. L. P. Rotondaro, R. Kuan, L. Tsung, M. Douglas, M. J. Bevan, H. Bu, A. Shanware, and L. Colombo, "Properties of Hf-based oxide and oxynitride thin films," in Proc. Int. Conf. Microelectron. Interf., 2002, pp. 127-129.

[6] J. A. Felix, J. R. Schwank, D. M. Fleetwood, M. R. Shaneyfelt, and E. P. Gusev, "Effects of radiation and charge trapping on the reliability of high-k gate dielectrics," Microelectron. Reliab., vol. 44, pp. 563-575, 2004.

[7] T. Watanabe, M. Takayanagi, R. Iijima, K. Ishimaru, H. Ishiuchi, and Y. Tsunashimd, "Design guideline of $\mathrm{HfSiON}$ gate dielectrics for 65 nm CMOS generation," VLSI Tech. Dig., pp. 19-20, 2003.

[8] J. A. Felix, D. M. Fleetwood, R. D. Schrimpf, J. G. Hong, G. Lucovsky, J. R. Schwank, and M. R. Shaneyfelt, "Total-dose radiation response of hafnium-silicate capacitors," IEEE Trans. Nucl. Sci., vol. 49, no. 6, pp. 3191-3196, Dec. 2002.

[9] J. A. Felix, M. R. Shaneyfelt, J. R. Schwank, P. E. Dodd, D. M. Fleetwood, X. J. Zhou, and E. P. Gusev, , E. Gusev, Ed., "The Effects of Radiation and Charge Trapping on the Reliability of Alternative Gate Dielectrics," in Defects in Advanced High- $\kappa$ Dielectric Nano-Electronic Semiconductor Devices. Amsterdam, The Netherlands: Springer-Verlag, 2006, pp. 299-322.

[10] X. J. Zhou, L. Tsetseris, S. N. Rashkeev, D. M. Fleetwood, R. D. Schrimpf, S. T. Pantelides, J. A. Felix, E. P. Gusev, and C. D'Emic, "Negative bias-temperature instabilities in Metal-Oxide-Silicon devices with $\mathrm{SiO}_{2}$ and $\mathrm{SiO}_{\mathrm{x}} \mathrm{N}_{\mathrm{y}} / \mathrm{HfO}_{2}$ gate dielectrics," Appl. Phys. Lett., vol. 84, pp. 4394-4396, 2004.

[11] X. J. Zhou, D. M. Fleetwood, J. A. Felix, E. P. Gusev, and C. D'Emic, "Bias-temperature instabilities and radiation effects in MOS devices," IEEE Trans. Nucl. Sci., vol. 52, pp. 2231-2238, 2005.

[12] X. J. Zhou, D. M. Fleetwood, L. Tsetseris, R. D. Schrimpf, and S. T. Pantelides, "Effects of switched-bias annealing on charge trapping in $\mathrm{HfO}_{2}$ gate dielectrics," IEEE Trans. Nucl. Sci., vol. 53, pp. 3636-3643, 2006.
[13] K. O. Jeppson and C. M. Svennson, "Negative bias stress of MOS devices at high electric fields and degradation of NMOS devices," J. Appl. Phys., vol. 48, pp. 2004-2014, 1977.

[14] D. M. Fleetwood, X. J. Zhou, L. Tsetseris, S. T. Pantelides, and R D. Schrimpf, R. E. Sah, M. J. Deen, J. Zhang, J. Yota, and Y. Kamakura, Eds., "Hydrogen model for negative-bias temperature instabilities in MOS gate insulators," in Proc. Silicon Nitride and Silicon Dioxide Thin Insulating Films and Other Emerging Dielectrics VIII, 2005, pp. 267-278.

[15] D. K. Schroder and J. A. Babcock, "Negative bias temperature instability: A road to cross in deep submicron CMOS manufacturing," $J$. Appl. Phys., vol. 94, pp. 1-18, 2003.

[16] L. Tsetseris, X. J. Zhou, D. M. Fleetwood, R. D. Schrimpf, and S. T. Pantelides, "Physical mechanisms of negative-bias temperature instability," Appl. Phys. Lett., vol. 86, 2005, art. no. 142103.

[17] G. Lucovsky, H. Seo, S. Lee, L. B. Fleming, M. D. Ulrich, J. Lüning, P. Lysaght, and G. Bersuker, "Intrinsic electronically-active defects in transition metal elemental oxides," Jpn. J. Appl. Phys., vol. 46, pp. 1899-1909, 2007.

[18] P. S. Winokur, J. R. Schwank, P. J. McWhorter, P. V. Dressendorfer, and D. C. Turpin, "Correlating the radiation response of MOS capacitors and transistors," IEEE Trans. Nucl. Sci., vol. 31, no. 6, pp. 1453-1460, Dec. 1984.

[19] R. Choi, S. J. Rhee, J. C. Lee, B. H. Lee, and G. Bersuker, "Charge trapping and detrapping characteristics in hafnium silicate gate stack under static and dynamic stress," IEEE Electron Dev. Lett., vol. 26, no. 3, pp. 197-199, Mar. 2005

[20] C. D. Young, Y. Zhao, M. Pendley, B. H. Lee, K. Matthews, J. H. Sim, R. Choi, G. A. Brown, R. W. Murto, and G. Bersuker, "Ultra-short pulse current-voltage characterization of the intrinsic characteristics of high-k devices," Jpn. J. Appl. Phys., vol. 44, pp. 2437-2440, 2005.

[21] D. M. Fleetwood, M. R. Shaneyfelt, W. L. Warren, J. R. Schwank, T. L. Meisenheimer, and P. S. Winokur, "Border traps: Issues for MOS radiation response and long-term reliability," Microelectron. Reliab., vol. 35, pp. 403-428, 1995.

[22] D. M. Fleetwood and N. S. Saks, "Oxide, interface, and border traps in thermal, $\mathrm{N}_{2} \mathrm{O}$, and $\mathrm{N}_{2} \mathrm{O}$-nitrided oxides," J. Appl. Phys., vol. 79, pp. 1583-1594, 1996.

[23] M. Houssa, M. Tuominen, M. Naili, V. Afanas'ev, A. Stesmans, S Haukka, and M. M. Heyns, "Trap-assisted tunneling in high permittivity gate dielectric stacks," J. Appl. Phys., vol. 87, pp. 8615-8620, 2000.

[24] M. R. Shaneyfelt, D. M. Fleetwood, J. R. Schwank, and K. L. Hughes, "Charge yield for 10-keV X-ray and cobalt-60 irradiation of MOS devices," IEEE Trans. Nucl. Sci., vol. 38, no. 1, pp. 1187-1194, Dec. 1991.

[25] S. L. Miller and P. J. McWhorter, "A predictive model of electron and hole decay in $\mathrm{SiN}-\mathrm{SiO}_{2}$ nonvolatile memory transistors experiencing arbitrary thermal environments," J. Appl. Phys., vol. 70, pp. 4569-4576, 1991.

[26] V. A. K. Raparla, S. C. Lee, R. D. Schrimpf, D. M. Fleetwood, and K. F. Galloway, "A model of radiation effects in nitride-oxide films for power MOSFET applications," Solid State Electron., vol. 47, pp. 775-783, 2003.

[27] G. Lucovsky, D. M. Fleetwood, S. Lee, H. Seo, R. D. Schrimpf, J. A. Felix, J. Lüning, L. B. Fleming, M. Ulrich, and D. E. Aspnes, "Differences between charge trapping states in irradiated nano-crystalline $\mathrm{HfO}_{2}$ and non-crystalline Hf silicates," IEEE Trans. Nucl. Sci., vol. 53, no. 6, pp. 3644-3648, Dec. 2006.

[28] J. M. Benedetto, H. E. Boesch, Jr., and F. B. McLean, "Dose and energy dependence of interface trap formation in colbalt-60 and X-ray Environments," IEEE Trans. Nucl. Sci., vol. 35, no. 1, pp. 1260-1264, Dec. 1988

[29] D. M. Fleetwood, R. A. Reber, P. J. McWhorter, P. S. Winokur, M. R. Shaneyfelt, and J. R. Schwank, "New insights into radiation-induced oxide-trap charge through thermally stimulated-current measurement and analysis," IEEE Trans. Nucl. Sci., vol. 39, no. 6, pp. 2192-2203, Dec. 1992.

[30] K. L. Brower, "Kinetics of $\mathrm{H}_{2}$ passivation of $\mathrm{P}_{\mathrm{b}}$ centers at the (111) Si-SiO ${ }_{2}$ interface," Phys. Rev. B., vol. 38, pp. 9657-9666, 1988.

[31] J. F. Zhang, S. Taylor, and W. Eccleston, "Electron trap generation in thermally grown $\mathrm{SiO}_{2}$ under Fowler-Nordheim stress," J. Appl. Phys., vol. 71, pp. 725-734, 1992.

[32] G. Pananakakis, G. Ghibaudo, R. Kies, and C. Papadas, "Temperature dependence of the Fowler-Nordheim current in metal-oxide-degenerate semiconductor structures," J. Appl. Phys., vol. 78, pp. 2635-2641, 1995. 